\title{
PENINGKATAN KEMAMPUAN KOGNITIF ANAK MELALUI PERMAINAN TABUNG MENGGUNAKAN BALOK ANGKA DAN HURUF
}

\author{
Ayu Mustika Sari \\ Program Study Pendidikan Anak Usia Universitas Dharmas Indonesia \\ Email : ayumustikasari10@gmail.com
}

\begin{abstract}
Abstrak
Penelitian ini bertujuan untuk meningkatkan kognitif anak TK Islam Terpadu Sungai Rumbai melalui penerapan permaian tabung dengan menggunakan balok angka dan huruf untuk peningkatan kemampuan kognitif pada bidang membaca dan menganal angka pada anak. Jenis penelitian ini adalah Penelitian Tindakan Kelas (PTK) yang dilaksanakan dalam dua siklus dengan 3 kali pertemuan setiap siklusnya. Setiap siklus terdiri dari beberapa tahap yaitu perencanaan, pelaksanaan tindakan, observasi dan refleksi, teknik pengumpulan data dilakukan dengan penilaan harian dan observasi. Hasil penelitian menunjukkan bahwa permaian tabung dengan menggunakan balok angka dan huruf dapat meningkatkan kemampuan kognitif anak pada bidang membaca dan menghitung. Mulai dari pratindakan, siklus I dan siklus II, yaitu 70\% anak berada pada tahap BB dan MB pada siklus I dan kembali meningkat menjadi $70 \%$ berada pada taraf MB dan BSH pada siklus II udah pertemuan ketiga $90 \%$ anak sudah berada pada taraf BSH dan BSB, berarti bahwa nilai yang diperoleh anak telah mencapai terget perkembangan kognitif. Oleh karenanya guru perlu meningkatkan keterampilan mengajarnya melalui penerapan permainan tabung angka dengan menggunakan balok angka dan huruf sebagai salah satu upaya yang dilakukan untuk meningkatkan aktivitas dan pencapaian target perkembagan kognitif anak.
\end{abstract}

Kata Kunci : Kognitif, Permainan tabung, balok angka, huruf.

\begin{abstract}
This study aims to improve the cognitive of Integrated Islamic Kindergarten children in Sungai Rumbai through the application of tube play using number and letter blocks to increase cognitive abilities in the field of reading and analyzing numbers in children. This type of research is Classroom Action Research $(C A R)$ which is carried out in two cycles with 3 meetings each cycle. Each cycle consists of several stages, namely planning, action, observation and reflection, data collection techniques carried out with daily assessment and observation.

The results of the study showed that tube playing using number and letter blocks can improve children's cognitive abilities in the field of reading and counting. Starting from pre-action, cycle I and cycle II, that is $70 \%$ of children in the BB and MB stages in the first cycle and again increased to $70 \%$ at the $\mathrm{MB}$ level and BSH in the second cycle after the third meeting $90 \%$ of children were at BSH level and BSB, means that the values obtained by children have reached cognitive development targets. Therefore teachers need to improve their teaching skills through the application of number tube games using number and letter blocks as one of the efforts made to increase the activity and achievement of the target of children's cognitive development.
\end{abstract}

Keywords: Cognitive, tube games, number blocks, letters.

(C) 2019 Ayu Mustika Sari

Under the license CC BY-SA 4.0

http://jurnal.upmk.ac.id/index.php/pelitapaud 


\section{PENDAHULUAN}

Aspek pengembangan yang akan penulis teliti adalah aspek pengembangan kognitif. kognitif adalah suatu proses berpikir berupa kemampuan untuk menghubungkan, menilai dan mempertimbangkan sesuatu, dapat juga dimaknai sebagai kemampuan untuk memecahkan masalah atau untuk mencipta karya yang dihargai dalam suatu kebudayaan. Salah satu aspek dalam pengembangan kognitif ini adalah pengembangan pembelajaran pengenalan huruf dan angka di Taman Kanak-kanak (TK).

Di Taman Kanak-kanak hanya diajarkan berhitung awal yaitu membilang dengan benda-benda 1 - 20, menyebutkan urutan bilangan 1-20, memasangkan lambang bilangan dengan benda 1-20, meniru lambang bilangan dengan benda 120, mampu membedakan 2 kumpulan benda sama jumlahnya, tidak sama jumlahnya, banyak dan sedikit jumlahnya. Sedangkan membaca pada anak-anak TK adalah terdiri dari beberapa tahapan yaitu tahap menyebutkan huruf dari a sampai z, mengenal huruf yang dari a sampai $\mathrm{z}$, mencocokan huruf dengan simbol huruf a sampai z. Tahapan dalam pelaksanaannya. berhitung dan membaca di TK dilakukan secara menarik dan bervariasi. Mengingat pentingnya kemampuan berhitung dan membaca, maka berhitung dan membaca dapat diberikan melalui berbagai macam cara yang menarik sehingga tidak meksa otak anak untuk berfikir.

Berdasarkan hasil penelitian dari Cahyati (2018) menunjukan bahwa perkembangan kognitif anak usia 5-6 tahun sudah mampu mengenal angka 1-20. Proses pembelajaran berhitung dan membaca permulaan yang diselenggarakan guru saat ini kurang mendukung keberhasilan belajar anak, di TK Islam Terpadum Yadiaksa Sungai Rumbai, guru kurang kreatif dalam menggunakan media pembelajaran berhitung dan membaca, media yang digunakan belum sesuai dengan konsep belajar anak yaitu Belajar Sambil Bermain dan akibatnya belum tercapainya tahapan perkembangan kognitif anak dengan maksimal.

Dasar pertimbangan pemilihan media permaina tabung dengan balok angka dan huruf untuk meningkatkan kemampuan berhitung dan membaca permulaan pada anak sebagai berikut: Pertama permainan tabung balok angka dan huruf mudah dimainkan oleh anak. Kedua permainan tabung balok angka dan huruf bertujuan untuk mengenalkan angka dan huruf pada anak sekaligus melatih motorik kasar karena dapat dikombinasikan dengan permainan lari atau gerakan motorik kasar lainnya. Ketiga Permainan tabung balok angka dan huruf dapat memberikan rasa senang sekaligus pengetahuan kepada anak 
sehingga anak dapat bermain sekaligus belajar. Keempat Permainan tabung balok angka dan huruf mengunakan tabung sebagai tempat bermain anak yang dapat dimodifikasi oleh guru sesuai kebutuhan pembelajaran berhitung dan membaca. Kelima bahan yang dipergunakan membuat media tabung balok angka dan huruf, adalah bahan bekas yang mudah didapatkan, tabung dibuat dari bekas ember cat, balok didapat dari potongan kayu sisa perabt yang dicat dengan diberi label angka dan huruf pada setiap balok.

\section{METODE PENELITIAN}

Pola pelaksanaan penelitian tindakan kelas ini menggunakan model siklus. Siklus ini terdiri dari empat komponen, yaitu perencanaan, tindakan, observasi, refleksi. Adapun model dan penjelasan untuk masing-masing tahap adalah sebagai berikut:

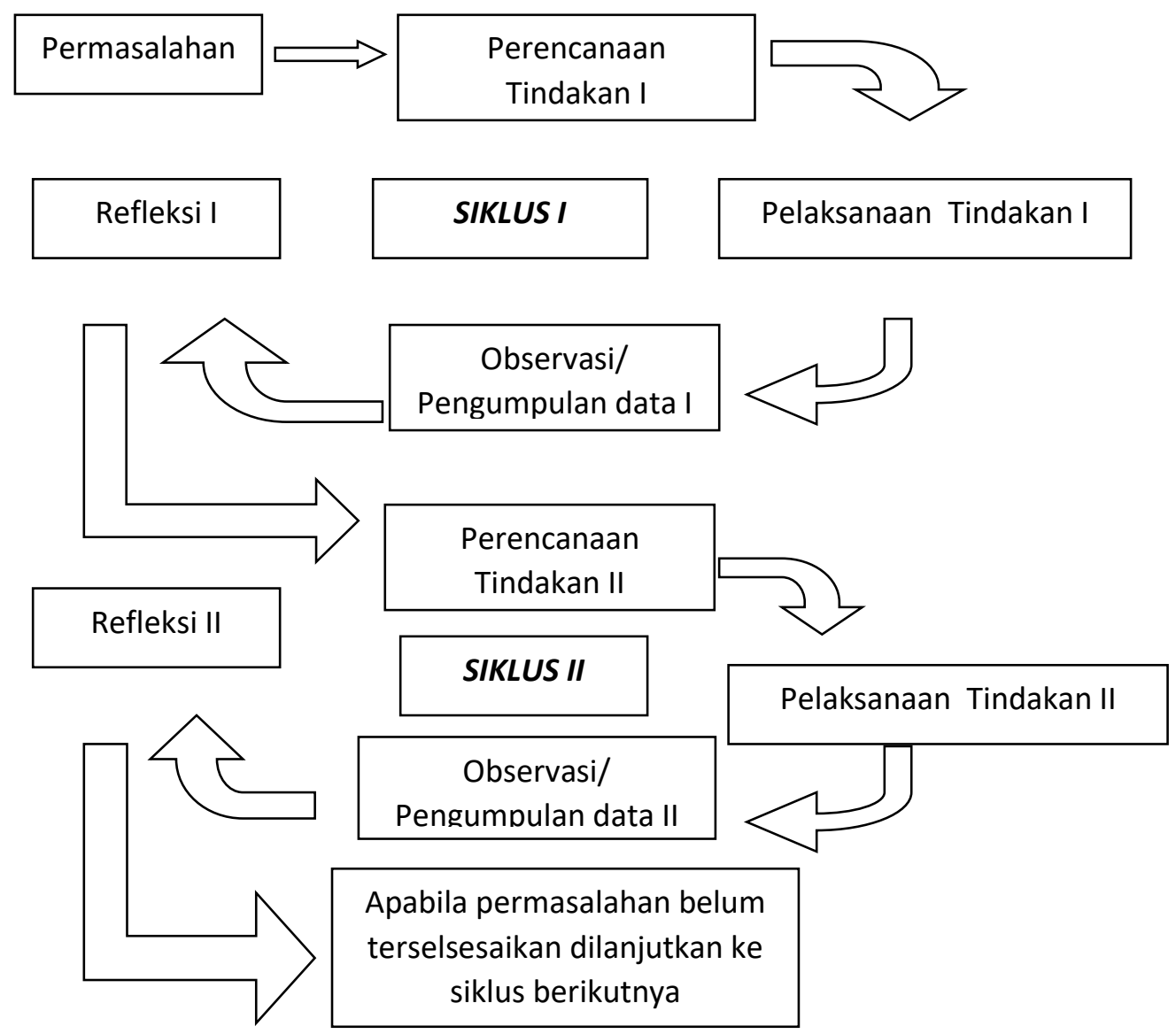

Gambar 1. Model Penelitian Tindakan Kelas Suharsimi Arikunto, (2006:16) 


\section{HASIL PENELITIAN DAN PEMBAHASAN}

Perencanaan

Perencanaan kegiatan pembelajaran mengenal angka dan huruf melalui permainan tabung dengan mengunakan balok angka dan huruf di KB IT Yadiaksa Sungai Rumbai Kab. Dharmasraya meliputi :

Perencanaan penyusunan RKH (Rencana Kegiatan Harian)

Pembuatan istrumen pokok penilaian peningkatan kemampuan mengenal huruf Menentukan jadwal pelaksanaan pembelajaran sesuai dengan waktu yang telah ditetapkan. Alokasi waktu setiap pertemuan selama 120 menit yang terbagi dalam 3 tahap yaitu kegiatan Awal (30 menit), kegiatan Inti (60 menit) dan kegiatan Akhir (30 menit). Adapun tindakan dalam siklus I akan dilaksanakan dalam 3 kali pertemuan. Pertemuan pertama dilaksanakan pada hari senin tanggal 5 Februari 2018, pertemuan kedua pada hari Rabu tanggal 7 Februari 2018, dan pertemuan ketiga pada hari kamis pada tanggal 8 Januari 2018.

Pelaksanaan

Pelaksanaan kegiatan pembelajaran mengenal angka dan huruf melalui permainan tabung menggunakan balok angka dan huruf di KB IT Yadiaksa Sungai Rumbai Kab.Dharmasraya siklus I dilaksanakan dengan 3 kali pertemuan.
Pertemuan pertama dilaksanakan pada hari senin tanggal 5 Maret 2018, pertemuan kedua pada hari Rabu tanggal 7 2018, dan Maret pertemuan ketiga pada hari kamis pada tanggal 8 Maret 2018.

Pelaksanaan pembelajaran di bagi dalam 3 tahap diantaranya :

Pendahuluan, pada tahap awal pembelajaran yaitu dimulai dengan kegiatan bermain dengan gerakan pemanasan sambil bernyanyi, guru mengucapkan salam, guru mengambil absen, sebelum belajar terlebih dahulu diawali dengan membaca doa dan hadist, selanjutnya guru menjelaskan aturan permainan Tabung dengan Menggunakan Balok Huruf dan Angka.

Kegiatan Inti, anak dikondisikan berkelompok di dalam ruangan, guru menjelaskan serta memberi contoh tentang permainan tabung dengan menggunakan balok huruf dan angka. Kemudian anakanak diajak mempraktikkan permainan tabung dengan menggunakan balok angka dan huruf. Masing-masing kelompok diberi tabung, balok angka dan huruf. Kemudian blok angka dan huruf ditumpuk secara tidak beraturan. Anak diminta ungurutkan angka dan huruf sesuai dengan contoh yang ada. Anak diminta menyebutkan huruf dan angka yang telah disusun. Permainan dimulai serentak sesuai dengan perintah guru, guru mengambil satu buah balok mengangkat 
balok anak berebut menjawab balok yang di angkat guru (a),guru memberi perintah coba ambil huruf yang sama dengan yang diperagakan guru, (b) anak berlomba pula mengambil huruf yang sama dengan yang diperagakan guru (c), setelah itu memberi masukan yang bisa diingat oleh anak sesuai dengan huruf yang diperangakan (d) gambar yang kita ingat apa dan begitu selanjutnya. setelah itu anak diperintahkan menyusun huruf sesuai gambar.contohnya. Matahari kelompok yang sudah selesai diminta untuk menyebutkan hurufnya. (e) setelah berhasil menyebutkan huruf anak diminta untuk melemparkan balok kedalam tabung sesuai dengan warna. (f) bagi yang duluan selesai melempar itulah pemenangnya. Bagi kelompok yang memenangkanya akan diberi pujian dan hadiah.
Pencatatan bagi anak yang mengenal angka dan huruf dan tidak mengenal huruf dalam membedakan huruf. Bagi anak yang dapat melakukan permainan lebih cepat dan benar, maka memberikan pujian dan hadiah berupa gambar-gambar kepada anak tersebut, hal ini dimaksudkan agar anak yang lainya termotivasi sehingga mau berusaha untuk meningkatkan pengetahuannya. Pada bagian akhir pembelajaran guru memberikan evaluasi dan menutup pembelajaran dan berdoa.

Pengamatan

Berdasarkan hasil kegiatan pembelajaran mengenal angka dan huruf melaui permainan tabung dengan menggunakan balaok angka dan huruf pada Siklus 1 pertemuan 1 dapat dilihat pada tabel 1 .

Tabel 1. Pengenalan angka dan Huruf Siklus 1.

\begin{tabular}{|c|c|c|c|c|c|c|c|c|c|}
\hline \multirow[t]{3}{*}{ No } & Aspek yang dinilai & \multicolumn{8}{|c|}{ Pengenalan Huruf Pertemuan 1} \\
\hline & & \multicolumn{2}{|l|}{ BB } & \multicolumn{2}{|c|}{ MB } & \multicolumn{2}{|c|}{ BSH } & \multicolumn{2}{|c|}{ BSB } \\
\hline & Mengenal Huruf & $\mathrm{F}$ & $\%$ & $\mathrm{~F}$ & $\%$ & $\mathrm{~F}$ & $\%$ & $\mathrm{~F}$ & $\%$ \\
\hline 1. & $\begin{array}{l}\text { Membilang /menyebut } \\
\text { urutan bilangan dari 1-10 }\end{array}$ & 0 & 0 & 1 & 10 & 8 & 60 & 1 & 10 \\
\hline 2. & $\begin{array}{l}\text { Ketepatan menunjuk dan } \\
\text { menirukan lambang bilangan }\end{array}$ & 2 & 20 & 4 & 40 & 3 & 30 & 1 & 10 \\
\hline \multirow[t]{2}{*}{3.} & $\begin{array}{l}\text { Memasangkan lambang } \\
\text { bilangan dengan benda }\end{array}$ & 0 & 0 & 5 & 50 & 3 & 30 & 2 & 20 \\
\hline & Mengenal Angka & $\mathrm{F}$ & $\%$ & $\mathrm{~F}$ & $\%$ & $F$ & $\%$ & $\mathrm{~F}$ & $\%$ \\
\hline 1. & $\begin{array}{l}\text { Menyebutkan huruf dari a } \\
\text { sampai z }\end{array}$ & 1 & 10 & 4 & 40 & 4 & 40 & 1 & 10 \\
\hline 2. & Mengenal huruf a sampai z & 2 & 20 & 4 & 40 & 3 & 30 & 1 & 10 \\
\hline 3. & $\begin{array}{l}\text { Mencocokkan huruf dengan } \\
\text { simbol huruf a sampai z }\end{array}$ & 0 & 0 & 4 & 40 & 3 & 30 & 2 & 35 \\
\hline
\end{tabular}


Hasil pengamatan pertemuan 2 terhadap peningkatan mampuan kognitif anak bidang pengenalan huruf dan angka melalui permainan tabung mengunakan

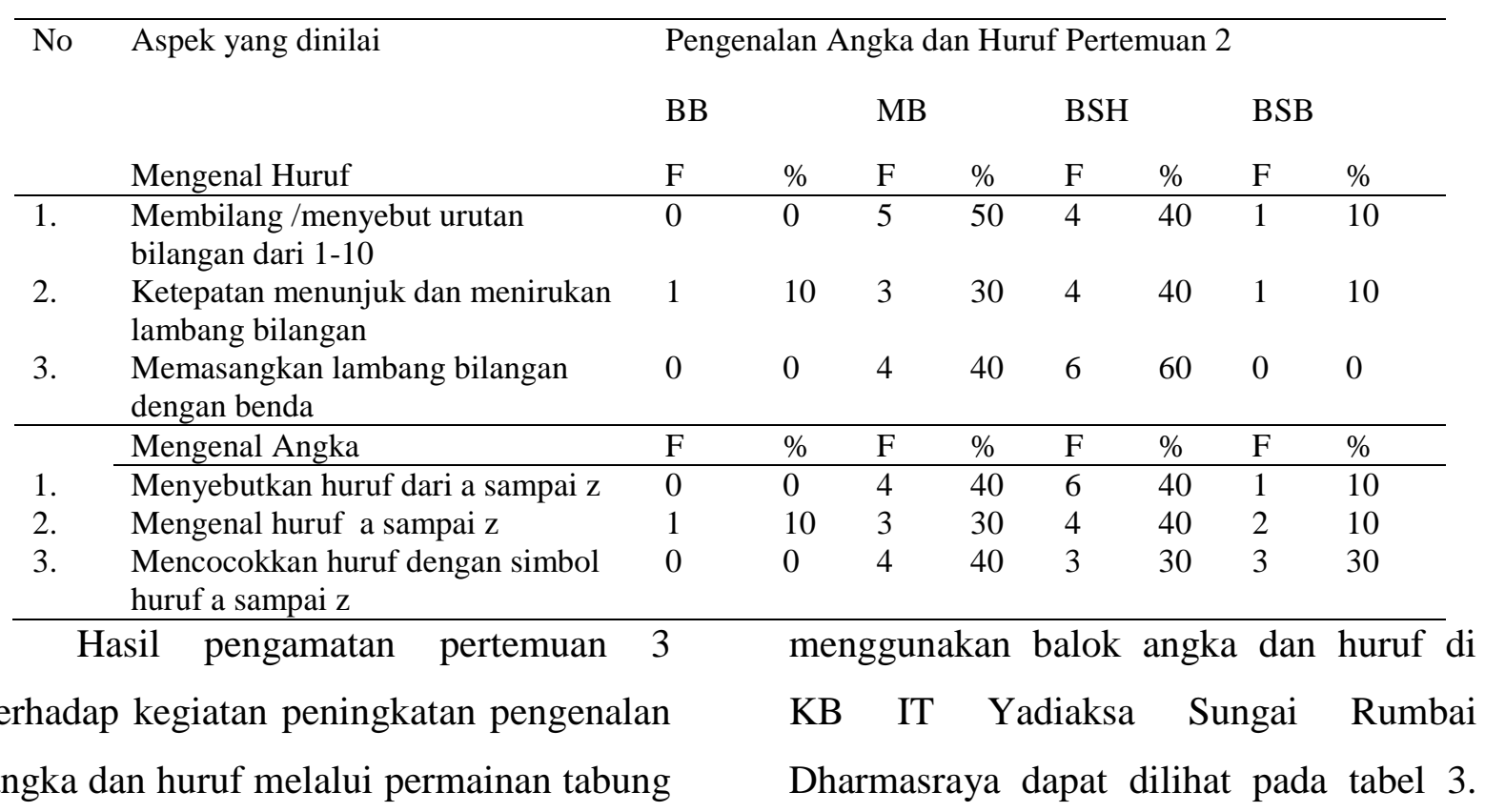
huruf a sampai z

\begin{tabular}{|c|c|c|c|c|c|c|c|c|c|}
\hline \multirow[t]{3}{*}{ No } & \multirow{3}{*}{$\begin{array}{l}\text { Aspek yang dinilai } \\
\text { Mengenal Huruf }\end{array}$} & \multicolumn{8}{|c|}{ Pengenalan Angka dan Huruf Pertemuan 2} \\
\hline & & \multicolumn{2}{|c|}{$\mathrm{BB}$} & \multicolumn{2}{|l|}{ MB } & \multicolumn{2}{|l|}{$\mathrm{BSH}$} & \multicolumn{2}{|l|}{ BSB } \\
\hline & & $\mathrm{F}$ & $\%$ & $\mathrm{~F}$ & $\%$ & $\mathrm{~F}$ & $\%$ & $\mathrm{~F}$ & $\%$ \\
\hline 1. & $\begin{array}{l}\text { Membilang /menyebut urutan } \\
\text { bilangan dari 1-10 }\end{array}$ & 0 & 0 & 5 & 50 & 4 & 40 & 1 & 10 \\
\hline 2. & $\begin{array}{l}\text { Ketepatan menunjuk dan menirukan } \\
\text { lambang bilangan }\end{array}$ & 1 & 10 & 3 & 30 & 4 & 40 & 1 & 10 \\
\hline \multirow[t]{2}{*}{3.} & $\begin{array}{l}\text { Memasangkan lambang bilangan } \\
\text { dengan benda }\end{array}$ & 0 & 0 & 4 & 40 & 6 & 60 & 0 & 0 \\
\hline & Mengenal Angka & $\mathrm{F}$ & $\%$ & $\mathrm{~F}$ & $\%$ & $\mathrm{~F}$ & $\%$ & $\mathrm{~F}$ & $\%$ \\
\hline 1. & Menyebutkan huruf dari a sampai z & 0 & 0 & 4 & 40 & 6 & 40 & 1 & 10 \\
\hline 2. & Mengenal huruf a sampai z & 1 & 10 & 3 & 30 & 4 & 40 & 2 & 10 \\
\hline 3. & $\begin{array}{l}\text { Mencocokkan huruf dengan simbol } \\
\text { huruf a sampai z }\end{array}$ & 0 & 0 & 4 & 40 & 3 & 30 & 3 & 30 \\
\hline & sil pengamatan pertemuan & 3 & \multicolumn{7}{|c|}{ menggunakan balok angka dan huruf di } \\
\hline & egiatan peningkatar & & $\mathrm{K}$ & IT & & laksa & & ngai & Rumbai \\
\hline
\end{tabular}
terhadap kegiatan peningkatan pengenalan KB IT Yadiaksa Sungai Rumbai angka dan huruf melalui permainan tabung Dharmasraya dapat dilihat pada tabel 3 .

Tabel 3. Pengenalan angka dan Huruf Siklus 1 Pertemuan 2

\begin{tabular}{|c|c|c|c|c|c|c|c|c|c|}
\hline \multirow[t]{3}{*}{ No } & \multirow{3}{*}{$\begin{array}{l}\text { Aspek yang dinilai } \\
\text { Mengenal Huruf }\end{array}$} & \multicolumn{8}{|c|}{ Pengenalan Angka Huruf Pertemuan 3} \\
\hline & & \multicolumn{2}{|c|}{ BB } & \multicolumn{2}{|c|}{ MB } & \multicolumn{2}{|c|}{ BSH } & \multicolumn{2}{|c|}{ BSB } \\
\hline & & $\mathrm{F}$ & $\%$ & $\mathrm{~F}$ & $\%$ & $\mathrm{~F}$ & $\%$ & $\mathrm{f}$ & $\%$ \\
\hline 1. & $\begin{array}{l}\text { Membilang /menyebut urutan } \\
\text { bilangan dari } 1-10\end{array}$ & 0 & 0 & 5 & 50 & 4 & 60 & 1 & 10 \\
\hline 2. & $\begin{array}{l}\text { Ketepatan menunjuk dan } \\
\text { menirukan lambang bilangan }\end{array}$ & 0 & 0 & 6 & 60 & 3 & 30 & 1 & 10 \\
\hline \multirow[t]{2}{*}{3.} & $\begin{array}{l}\text { Memasangkan lambang } \\
\text { bilangan dengan benda }\end{array}$ & 0 & 0 & 4 & 40 & 5 & 50 & 1 & 10 \\
\hline & Mengenal Angka & $\mathrm{F}$ & $\%$ & $\mathrm{~F}$ & $\%$ & $\mathrm{~F}$ & $\%$ & f & $\%$ \\
\hline 1. & $\begin{array}{l}\text { Menyebutkan huruf dari a } \\
\text { sampai z }\end{array}$ & 0 & 0 & 5 & 50 & 4 & 40 & 1 & 10 \\
\hline 2. & Mengenal huruf a sampai z & 0 & 0 & 6 & 60 & 4 & 40 & 0 & 0 \\
\hline 3. & $\begin{array}{l}\text { Mencocokkan huruf dengan } \\
\text { simbol huruf a sampai z }\end{array}$ & 0 & 0 & 5 & 50 & 4 & 40 & 1 & 10 \\
\hline
\end{tabular}

Kec.Sungai Rumbai Kab. Dharmasraya dapat dilihat pada tabel 2 :

Tabel 2. Pengenalan angka dan Huruf Siklus 1 Pertemuan 2.

Berdasarkan tabel diatas dapat kita amati bahwa terjadi pengingkatan kognitif
anak setelah belajar melalui permainan

amati bahwa terjadi pengingkatan kognitif
anak setelah belajar melalui permainan

tabung menggunakan balok angka dan huruf di KB IT Yadiaksa. Namun taraf keberhasilan belum mencapai $70 \%$ unatuk 
nilai BSH dan BSB maka perlunya dilanjutkan penelitian berikutnya.

Refleksi Siklus I

Berdasarkan hasil penelitian yang telah dilakukan pada siklus I maka pelaksanaan pembelajaran siklus I sudah sesuai dengan rencana Berdasarkan hasil pengamatan dampak pembelajaran sudah cukup berhasil, namun belum menjukkan peningkatan kemapauan yang signifikan. Untuk mengatasi hal tersebut di atas maka dilakukan hal-hal sebagai berikut, menvariasikan media dan strategi permainan, memberikan bimbingan kepada anak, memberikan kesempatan kepada anak untuk melakukan kegiatan agar mereka dapat memperoleh pengalaman secara langsung, sehingga pembelajaran lebih bermakna, mendampingi anak secara individual terutama bagi anak-anak yang masih mengalami kesulitan melakukan permaianan.

Siklus II

Perencanaan

Perencanaan Peningkatan Kognitif anak dibidang pembelajaran mengenal angka dan huruf melalui permainan tabung dengan mengunakan balok angka dan huruf di KB IT Yadiaksa Sungai Rumbai Kab. Dharmasraya meliputi perencanaan penyusunan RKH. Pembuatan istrumen pokok penilaian peningkatan kemampuan mengenal huruf. Menentukan jadwal pelaksanaan pembelajaran sesuai dengan waktu yang telah ditetapkan. Alokasi waktu setiap pertemuan selama 120 menit yang terbagi dalam 3 tahap yaitu kegiatan Awal (30 menit), kegiatan Inti (60 menit) dan kegiatan Akhir (30 menit). Adapun tindakan dalam siklus I akan dilaksanakan dalam 3 kali pertemuan. Pertemuan pertama dilaksanakan pada hari senin tanggal 12 Februari 2018, pertemuan kedua pada hari Rabu tanggal 14 Februari 2018, dan pertemuan ketiga pada hari kamis pada tanggal 15 Januari 2018.

Pelaksanaan

Pelaksanaan kegiatan pembelajaran mengenal angka dan huruf melalui permainan tabung menggunakan balok angka dan huruf di KB IT YADIAKSA Sungai Rumbai Kab.Dharmasraya siklus I dilaksanakan dengan 3 kali pertemuan. Pertemuan pertama dilaksanakan pada hari senin tanggal 12 Maret 2018, pertemuan kedua pada hari Rabu tanggal 14 februari 2018, dan pertemuan 3pada hari kamis pada tanggal 15 Maret 2018.

Pelaksanaan pembelajaran di bagi dalam 3 tahap diantaranya, pada tahap awal pembelajaran yaitu dimulai dengan kegiatan bermain dengan gerakan pemanasan sambil bernyanyi. Guru mengucapkan salam. Guru mengambil absen, sebelum belajar terlebih dahulu diawali dengan membaca doa dan hadist. Selanjutnya guru menjelaskan aturan 
permainan Tabung dengan Menggunakan Balok Huruf dan Angka.

Kegiatan Inti anak dikondisikan berkelompok di dalam ruangan, memilih kelompok yang cocok untuk anak dengan memeprtimbangakan tipe-tipe anak dan tingkat kemampuan anak. Guru menjelaskan serta memberi contoh tentang permainan tabung dengan menggunakan balok huruf dan angka. Kemudian anakanak diajak mempraktikkan permainan tabung dengan menggunakan balok angka dan huruf. Masing-masing kelompok diberi tabung, balok angka dan huruf. Kemudian blok angka dan huruf ditumpuk secara tidak beraturan. Anak diminta ungurutkan angka dan huruf sesuai dengan contoh yang ada. Anak diminta menyebutkan huruf dan angka yang telah disusun. Permainan dimulai serentak sesuai dengan perintah guru, guru mengambil satu buah balok mengangkat balok anak berebut menjawab balok yang di angkat guru (a),guru memberi perintah coba ambil huruf yang sama dengan yang diperagakan guru, (b) anak berlomba pula mengambil huruf yang sama dengan yang diperagakan guru (c), setelah itu memberi masukan yang bisa diingat oleh anak sesuai dengan huruf yang diperangakan (d) gambar yang kita ingat apa dan begitu selanjutnya. setelah itu anak diperintahkan menyusun huruf sesuai gambar.contohnya. Matahari kelompok yang sudah selesai diminta untuk menyebutkan hurufnya. (e) setelah berhasil menyebutkan huruf anak diminta untuk melemparkan balok kedalam tabung sesuai dengan warna. (f) bagi yang duluan selesai melempar itulah pemenangnya.

Penutup, pencatatan bagi anak yang mengenal angka dan huruf dan tidak mengenal huruf dalam membedakan huruf. Bagi anak yang dapat melakukan permainan lebih cepat dan benar, maka memberikan pujian dan hadiah berupa gambar-gambar kepada anak tersebut, hal ini dimaksudkan agar anak yang lainya termotivasi sehingga mau berusaha untuk meningkatkan pengetahuannya. Pada bagian akhir pembelajaran guru memberikan evaluasi dan menutup pembelajaran dan berdoa.

Pengamatan

Berdasarkan hasil kegiatan pembelajaran mengenal angka dan huruf melaui permainan tabung dengan menggunakan balok angka dan huruf pada Siklus 2 pertemuan 1 dapat dilihat pada tabel 4. 
Tabel 4. Pengenalan angka dan Huruf. Siklu 2 Pertemuan 1.

\begin{tabular}{|c|c|c|c|c|c|c|c|c|c|}
\hline \multirow[t]{3}{*}{ No } & \multirow{3}{*}{$\begin{array}{l}\text { Aspek yang dinilai } \\
\text { Mengenal Huruf }\end{array}$} & \multicolumn{8}{|c|}{ Pengenalan Huruf Pertemuan 1} \\
\hline & & \multicolumn{2}{|c|}{$\mathrm{BB}$} & \multicolumn{2}{|c|}{$\mathrm{MB}$} & \multicolumn{2}{|c|}{$\mathrm{BSH}$} & \multicolumn{2}{|c|}{ BSB } \\
\hline & & $\mathrm{F}$ & $\%$ & $\mathrm{~F}$ & $\%$ & $\mathrm{~F}$ & $\%$ & $\mathrm{~F}$ & $\%$ \\
\hline 1. & $\begin{array}{l}\text { Membilang /menyebut urutan } \\
\text { bilangan dari } 1-10\end{array}$ & 0 & 0 & 2 & 20 & 4 & 40 & 3 & 30 \\
\hline 2. & $\begin{array}{l}\text { Ketepatan menunjuk dan } \\
\text { menirukan lambang bilangan }\end{array}$ & 0 & 0 & 2 & 20 & 4 & 40 & 3 & 30 \\
\hline \multirow[t]{2}{*}{3.} & $\begin{array}{l}\text { Memasangkan lambang } \\
\text { bilangan dengan benda }\end{array}$ & 0 & 0 & 2 & 20 & 6 & 60 & 2 & 20 \\
\hline & Mengenal Angka & $\mathrm{F}$ & $\%$ & $\mathrm{~F}$ & $\%$ & $\mathrm{~F}$ & $\%$ & $\mathrm{~F}$ & $\%$ \\
\hline 1. & $\begin{array}{l}\text { Menyebutkan huruf dari a } \\
\text { sampai z }\end{array}$ & 0 & 0 & 2 & 20 & 4 & 40 & 4 & 40 \\
\hline 2. & Mengenal huruf a sampai z & 0 & 0 & 3 & 30 & 5 & 50 & 2 & 20 \\
\hline 3. & $\begin{array}{l}\text { Mencocokkan huruf dengan } \\
\text { simbol huruf a sampai z }\end{array}$ & 0 & 0 & 1 & 10 & 7 & 70 & 2 & 20 \\
\hline
\end{tabular}

Hasil pengamatan pertemuan 2 tabung dengan menggunakan balok angka terhadap kegiatan peningkatan kognitif anak dalam bidang kemapuan mengenal dan huruf di KB IT YADIAKSA Sungai angka dan huruf melalui permainan Rumbai Kab.Dharmasraya dapat dilihat Tabel 5. Pengenalan angka dan Huruf Siklus 2 Pertemuan 2.

\begin{tabular}{|c|c|c|c|c|c|c|c|c|c|}
\hline \multirow[t]{3}{*}{ No } & \multirow{3}{*}{$\begin{array}{l}\text { Aspek yang dinilai } \\
\text { Mengenal Huruf }\end{array}$} & \multicolumn{8}{|c|}{ Pengenalan Angka dan Huruf Pertemuan 2} \\
\hline & & \multicolumn{2}{|c|}{$\mathrm{BB}$} & \multicolumn{2}{|c|}{ MB } & \multicolumn{2}{|c|}{$\mathrm{BSH}$} & \multicolumn{2}{|c|}{ BSB } \\
\hline & & $\mathrm{F}$ & $\%$ & $\mathrm{~F}$ & $\%$ & $\mathrm{~F}$ & $\%$ & $\mathrm{~F}$ & $\%$ \\
\hline 1. & $\begin{array}{l}\text { Membilang /menyebut urutan } \\
\text { bilangan dari 1-10 }\end{array}$ & 0 & 0 & 2 & 20 & 7 & 70 & 1 & 10 \\
\hline 2. & $\begin{array}{l}\text { Ketepatan menunjuk dan } \\
\text { menirukan lambang bilangan }\end{array}$ & 0 & 0 & 1 & 10 & 6 & 60 & 3 & 30 \\
\hline \multirow[t]{2}{*}{3.} & $\begin{array}{l}\text { Memasangkan lambang bilangan } \\
\text { dengan benda }\end{array}$ & 0 & 0 & 0 & 0 & 7 & 70 & 3 & 30 \\
\hline & Mengenal Angka & $\mathrm{F}$ & $\%$ & $\mathrm{~F}$ & $\%$ & $\mathrm{~F}$ & $\%$ & $\mathrm{~F}$ & $\%$ \\
\hline 1. & $\begin{array}{l}\text { Menyebutkan huruf dari a } \\
\text { sampai z }\end{array}$ & 0 & 0 & 1 & 10 & 6 & 40 & 3 & 30 \\
\hline 2. & Mengenal huruf a sampai z & 0 & 0 & 2 & 30 & 6 & 40 & 2 & 20 \\
\hline 3. & $\begin{array}{l}\text { Mencocokkan huruf dengan } \\
\text { simbol huruf a sampai z }\end{array}$ & 0 & 0 & 2 & 40 & 5 & 30 & 3 & 30 \\
\hline
\end{tabular}

Hasil pengamatan pertemuan 3 terhadap kegiatan peningkatan pengenalan angka dan huruf melalui permainan tabung menggunakan balok angka dan huruf di KB IT Yadiaksa Sungai Rumbai Dharmasraya dapat dilihat pada tabel 6. 
Tabel 6. Pengenalan angka dan Huruf Siklus 2 Pertemuan 3.

\begin{tabular}{|c|c|c|c|c|c|c|c|c|c|}
\hline \multirow[t]{3}{*}{ No } & \multirow{3}{*}{$\begin{array}{l}\text { Aspek yang dinilai } \\
\text { Mengenal Huruf }\end{array}$} & \multicolumn{8}{|c|}{ Pengenalan Angka Huruf Pertemuan 3} \\
\hline & & \multicolumn{2}{|c|}{$\mathrm{BB}$} & \multicolumn{2}{|c|}{ MB } & \multicolumn{2}{|c|}{$\mathrm{BSH}$} & \multicolumn{2}{|c|}{ BSB } \\
\hline & & $\mathrm{F}$ & $\%$ & $\mathrm{~F}$ & $\%$ & $\mathrm{~F}$ & $\%$ & $f$ & $\%$ \\
\hline 1. & $\begin{array}{l}\text { Membilang /menyebut urutan } \\
\text { bilangan dari } 1-10\end{array}$ & 0 & 0 & 1 & 10 & 8 & 80 & 1 & 10 \\
\hline 2. & $\begin{array}{l}\text { Ketepatan menunjuk dan } \\
\text { menirukan lambang bilangan }\end{array}$ & 0 & 0 & 0 & 0 & 7 & 70 & 3 & 30 \\
\hline \multirow[t]{2}{*}{3.} & $\begin{array}{l}\text { Memasangkan lambang } \\
\text { bilangan dengan benda }\end{array}$ & 0 & 0 & 0 & 0 & 5 & 50 & 5 & 50 \\
\hline & Mengenal Angka & $\mathrm{F}$ & $\%$ & $\mathrm{~F}$ & $\%$ & $\mathrm{~F}$ & $\%$ & $\mathrm{~F}$ & $\%$ \\
\hline 1. & $\begin{array}{l}\text { Menyebutkan huruf dari a } \\
\text { sampai z }\end{array}$ & 0 & 0 & 1 & 10 & 5 & 50 & 4 & 40 \\
\hline 2. & Mengenal huruf a sampai z & 0 & 0 & 1 & 10 & 6 & 60 & 3 & 30 \\
\hline 3. & $\begin{array}{l}\text { Mencocokkan huruf dengan } \\
\text { simbol huruf a sampai z }\end{array}$ & 0 & 0 & 0 & 0 & 6 & 60 & 4 & 40 \\
\hline
\end{tabular}

Refleksi siklus II

Berdasarkan hasil pengamatan dampak pembelajaran sudah berhasil dengan traf keberhasilan $90 \%$ anak sudah berapada pada taraf BSH dan BSB.

\section{SIMPULAN}

Berdasarkan hasil penelitian dan pembahasan yang telah diuraikan pada bab sebelumnya, maka dapat di ambil kesimpulan bahwa berdasarkan penelitian yang telah penulis lakukan bahwa melalui permainan tabung dengan menggunakan balok angka dan huruf dapat meningkatkan kemampuan kognitif anak dalam bidang kemapuan mengenal angka dan huruf. Kemampuan menunjuk angka dalam menjukakan lambang biangan, mengenali bilangan dan mencocokakan bilangan meningkat signifikan dengan 90
$\%$ anak berapada pada taraf Berkembangna Sangat Baik (BSB) dan Berkembang sesuai harapan BSH. Kemampuan menunjuk huruf, mengenali huruf dan mencocokkan huruf dari a samapi z meningkat secara signifikan dari siklus 1 kesiklus 2, yaitu 90\% anak berada pada dengan kegiatan belajar yang membtaraf Berkembang Sangat Baik (BSB) dan Berkembang Sesuia Harapan (BSH).

\section{DAFTAR PUSTAKA}

Arikunto, Suharsimi. (2010). Prosedur penelitian. Jakarta: PT Rineka.

Cahyati, Nika. (2018). Kemampuan mengenal angka melalui media memancing bola angka. Jurnal pelita PAUD, Vol.3 No.1, p.328333. 
Dadan, Suryana. (2013). Pendidikan Anak Usia Dini. Padang: Sukabina Press

Depdiknas. (2003). Undang-Undang No. 20 Tahun 2003 tentang Sistem Pendidikan Nasional. Jakarta

http//www.crayonpedia.org/mw/tabung kerucut dan bola

http://books.google.co.id/books?id=6yiMc 3BP0b0C\&pg=PA195\&dq=sifatsifat+tabung\&h

Jamal, Ma;mur Asmani. (2015). Panduan Praktis Manajemen Mutu Guru PAUD. Yogyakarta : Diva Press

Mahyuddin. (2008). Asesmen Anak Usia Dini. Padang: UNP Press

Mulyasa. (2012). Manajemen Paud. Bandung: PT Remaja Rosdakarya

Rachmawati, Yeni \& Euis Kurniati. (2010). Strategi Pengembangan Kreativitas Anak TK. Jakarta: Kencana Prenada Media Group

Sri, Mulyanti. (2013). Perkembangan Psikologi Anak. Yogyakarta:Laras Media Rima

Sugiyono. (2013). Metode Penelitian Kuantitatif, Kualitatif, dan $R \& D$. Bandung: Alfabeta

Sujiono, Yuliani Nurani. (2009). Bermain Kreatif Berbasis Kecerdasan Jamak. Jakarta: PT. Indeks

Suyadi dan Maulidya Ulfah. (2013). Konsep Dasar PAUD. Bandung: PT RemajaRosdakarya

Suyanto, Slamet. (2005). Konsep Dasar Pendidikan Anak Usia Dini. Jakarta: Depdiknas

Syafril. (2010). Statistika. Padang: Sukabina Press
Trianto. (2011). Desain Pengembangan Pembelajaran Tematik. Jakarta :Kencana Prenada Media Group

Yulsyofriend. (2013). Permainan Membaca dan Menulis Anak Usia Dini. Padang: Sukabina Press 